\title{
Determinan Penggunaan Kondom pada Penjaja Seks Komersial (PSK) di Kawasan Sicanang Belawan
}

\author{
Eva $^{1}$, Fridalina ${ }^{2}$ \\ Program Studi Magister I Imu Kesehatan Masyarakat, Pascasarjana Universitas Sari Mutiara Indonesia Medan \\ J alan Kapten Muslim, Helvetia Tengah, Medan Helvetia, Dwi Kora, \\ Medan Helvetia Kota Medan, Sumatera Utara 20124 \\ Email : ${ }^{1}$ eva.dewierlitna@yahoo.co.id, 2 fridalina_tarigan@yahoo.com
}

\begin{abstract}
Abstrak
Data Profil Kesehatan Kota Medan tahun 2014 menunjukkan bahwa jumlah penderita infeksi menular seksual (IMS) sebanyak 2.203 orang. Data yang diperoleh dari 33 puskesmas se-Kota Medan bahwa jumlah penderita HIVIAIDS tertinggi pada tahun 2014 berada di Belawan sebanyak 15 orang. Tujuan penelitian ini adalah untuk mengetahui determinan penggunaan kondom pada penjaja seks komersial di kawasan Sicanang Belawan tahun 2017. Jenis penelitian ini adalah survei analitik atau explanatory dengan desain cross sectional. Penelitian ini menggunakan metode campuran (mix method), Populasi penelitian sebanyak 84 orang PSK di Sicanang Belawan dan seluruhnya dijadikan sampel. Analisis data menggunakan analisis univariat, analisis bivariat dengan uji chi-square, dan analisis multivariat dengan uji regresi logistik ganda. Hasil penelitian diperoleh bahwa dukungan mucikari merupakan determinan yang dominan berhubungan terhadap penggunaan kondom. PSK yang mendapat dukungan mucikari yang baik mempunyai peluang menggunakan kondom sebesar 6,7 kali lebih besar (Exp $B=6,756)$ dibandingkan dengan PSK yang tidak mendapatkan dukungan mucikari. Sehubungan dengan hal tersebut berarti bahwa determinan yang berhubungan dengan penggunaan kondom adalah pengetahuan, ketersediaan kondom, kenyamanan pelanggan, dan dukungan mucikari, dimana dukungan mucikari merupakan determinan yang dominan. Sementara persepsi dan dukungan tenaga kesehatan merupakan determinan yang tidak berhubungan terhadap penggunaan kondom Dengan demikian diharapkan kepada Kepala Puskesmas Belawan melakukan program penyuluhan dan pemeriksaan kesehatan kepada PSK di wilayah kerjanya dengan meningkatkan frekuensi menjadi 2-4 kali dalam sebulan.
\end{abstract}

Kata kunci : : Determinan, Kondom, Pekerja Seks Komersial (PSK)

\begin{abstract}
Data of Medan City Health Profile in 2014 shows that the number of sexually transmitted infections (IMS) as many as 2,203 people. Data obtained from 33 health centers in Medan City that the number of people living with HIV I AIDS in 2014 is in Belawan as many as 15 people. The purpose of this study is to determine the determinants of condom use in commercial sex workers in the area Sicanang Belawan 2017. Type of this study is an analytical survey or explanatory with cross sectional design. This research used mixed method (mix method). The population of the study were 84 people of PSK in Sicanang Belawan and all were sampled. Data were analyzed using univariate analysis, bivariate analysis with chi-square test, and multivariate analysis with multiple logistic regression test. The result showed that while pimp support is the dominant determinant associated with condom use. PSKs with good pimping support have an opportunity to use condoms as much as 6,7 times ((Exp $B=6,756)$ greater than those of prostitutes who do not get pimping support. In this respect, the determinants associated with condom use are knowledge, condom availability, customer comfort, and pimping support, where pimping support is the dominant determinant. While the perception and support of health personnel is an unrelated determinant of condom use. Thus, it is expected that Head of Puskesmas Belawan conduct health education and health inspection program to PSK in its working area by increasing the frequency to 2-4 times in a month.
\end{abstract}

Keywords : Determinant of Condom Use, Commercial Sex Workers 


\section{Pendahuluan}

Kondom diperkirakan telah memiliki sejarah yang panjang dalam perannya sebagai "alat pelindung". Sekitar 1.000 tahun sebelum Masehi, orang Mesir kuno telah menggunakan sarung pengaman untuk mencegah penyakit.Tahun 1500-an untuk pertama kali dipublikasikan deskripsi dan percobaan alat pencegah penyakit berupa kondom di Italia. Ketika itu Gabrielle Fallopius mengklaim menemukan kondom yang terbuat dari linen dan membuat uji coba pada 1.100 pria. Dari percobaan tersebut, tak satupun dari mereka yang terinfeksi penyakit sifilis.Penemuan membuktikan bahwa kain linen itu bermanfaat mencegah infeksi. ${ }^{1}$

Seiring dengan berkembangnya teknologi, proses pembuatan kondom menghasilkan kondom yang lebih kuat, lebih tipis, lebih lentur saat dipakai sehingga para pengguna kondom tidak hanya dapat merasa aman tetapi juga merasa nyaman.Pemakaian kondom mulai meredup seusai perang dunia II. Pada akhir 1960-an terjadi revolusi perilaku seksual manusia, terutama di Amerika. Hubungan seksual sebelum menikah dan di luar pernikahan makin terbuka, khususnya pada kaum wanita. Mereka menuntut hak yang sama seperti kaum pria yang bebas melakukan hubungan seksual dengan siapa saja. Akibatnya, para pria lebih memilih berhubungan seks dengan wanita bukan PSK (Penjaja Seks Komersial) yang dianggap lebih "bersih". Kondom dianggap tidak diperlukan lagi. Penggunaan kondom semakin menurun semenjak munculnya obat-obat antibiotik baru yang bisa menyembuhkan penyakitpenyakit kelamin klasik seperti sipilis atau gonorrhea. Selain itu, dengan ditemukannya alat-alat kontrasepsi baru yang lebih praktis dan nyaman, seperti Intra Uterine Device (IUD) dan pil, membuat orang lebih memilih mereka dari pada kondom. Penggunaan kondom mulai dikenal baik pada tahun 1980-an saat Acquired Immuno Deficiency Syndrome (AIDS) mulai merebak ke segala penjuru dunia. Meskipun bukan satu-satunya cara, kondom masih terbilang cara yang paling praktis dan gampang untuk mencegah penularan penyakit menular seksual termasuk HIV/AIDS, terutama bagi orangorang yang bekerja di dunia pelacuran. ${ }^{2}$

Sejak kasus pertama Human Immuno Virus (HIV) positif pada manusia ditemukan pada tahun 1959 dan kemudian kasus pertama AIDS pada tahun 1981 di Amerika Serikat, HIV/AIDS menjadi permasalahan utama bagi kesehatan di seluruh dunia (Kenderwis, 2008). Data World Health Organization (WHO) dalam laporan kemajuan 2014 (Global HIV/AIDS Respons, Progress Report 2014) melaporkan bahwa pada akhir tahun 2014 diperkirakan 34 juta orang (31.600.00035.200.000) hidup dengan HIV di seluruh dunia, termasuk 3,4 juta anak-anak berumur kurang dari 15 tahun. Ada 2,7 juta (2.400.000-2.900.000) baru terinfeksi HIV pada tahun 2013, termasuk 390.000 anak diantaranya berumur kurang dari 15 tahun. ${ }^{3}$

Data laporan dari Direktorat Jenderal Pengendalian Penyakit Menular dan Penyehatan Lingkungan (2014), angka kasus HIV/AIDS di Indonesia terus mengalami peningkatan, sampai Desember 2014 terdapat 24.131 kasus HIV dan 17.998 kasus AIDS, dengan jumlah kematian 1.994 ODHA (37,8\%). Proporsi kasus AIDS pada jenis kelamin laki-laki mencapai $62,7 \%$ dan perempuan adalah $37,3 \%{ }^{4}$

Hasil penelitian Surveilans Terpadu Biologis dan Perilaku (STBP) tahun 2014 yang melakukan penelitian di 23 Kabupaten/Kota di 11 Provinsi di Indonesia mendapatkan hasil bahwa Prevalensi HIV tertinggi terdapat pada Pengguna Napza Suntik (Penasun) yaitu $41 \%$, diikuti waria yaitu 22\%, Wanita Penjaja Seks Langsung (WPSL) yaitu 10\%, Lelaki Seks Lelaki (LSL) yaitu 8\%, Warga Binaan Pemasyarakatan (WBP) yaitu 3\%, Wanita Penjaja Seks Tidak Langsung (WPSTL) yaitu 3\%, dan pria potensial risiko tinggi yaitu $0,7 \%{ }^{5}$ 
Bila dikaitkan dengan indikator keberhasilan program pengendalian HIV/AIDS di Indonesia, maka hasil STPB 2014 menunjukkan bahwa persentase penggunaan kondom dalam seminggu terakhir pada perempuan (dalam hal ini WPSL) adalah sebesar 35\% dan pada lakilaki (dalam hal ini pria potensial risiko tinggi) dalam setahun terakhir adalah sebesar 14\%. Dengan demikian, pencapaian indikator keberhasilan penggunaan kondom pada kelompok berisiko tinggi tahun 2014 adalah sebesar 100\% pada perempuan (target tahun 2014: $35 \%$ ) dan $70 \%$ pada laki-laki (target tahun 2014: 20\%). ${ }^{4}$

Berdasarkan data dari profil Kesehatan Provinsi Sumatera Utara tahun 2014 bahwa dalam sepuluh tahun terakhir, jumlah penderita HIV/AIDS meningkat tajam. Jumlah kasus HIV (+) meningkat dari 883 kasus pada tahun 2009 menjadi 2.063 kasus, dan kasus AIDS meningkat dari 1.351 kasus menjadi 1.476 kasus. Berdasarkan karakteristik penderita diketahui bahwa penderita terbanyak adalah pria $(77,8 \%)$, wanita $(20,4 \%)$, dan waria $(1,8 \%)$. Sumber penularan terbanyak melalui hubungan heteroseksual 44,5\% dan pengguna jarum suntik 40,4\%. Berdasarkan golongan umur yaitu 82,53\% adalah kelompok usia 20-39 tahun. Penderita HIV/AIDS terbanyak adalah Kota Medan yaitu 1.715 kasus (68,30\%) dari total seluruh penderita. ${ }^{6}$

Berdasarkan data yang diperoleh dari Puskesmas Belawan bahwa jumlah PSK sebanyak 84 orang yang tersebar di tempat-tempat khusus atau barak yaitu Barak Agen, Barak Agung, Barak Sempurna, Barak Oukup dan Barak Salon. Kasus IMS dan HIV/AIDS yang dilaporkan di Puskesmas Belawan pada tahun 2016 sebanyak 9 orang.Pada bulan Januari sebanyak 3 orang (2 orang IMS, 1 orang HIV/AIDS), bulan Februari sebanyak 2 orang IMS, bulan Juli sebanyak 1 orang IMS, bulan November sebanyak 2 orang (1 orang IMS, 1 orang HIV/AIDS), dan bulan Desember sebanyak 1 orang HIV. Untuk pencegahan penyebaran penyakit IMS dan HIV/AIDS pihak Puskesmas Belawan membagikan kondom secara gratis kepada para PSK di barak-barak yang ada di wilayah kerja Puskesmas Belawan. Jumlah kondom yang dibagikan kepada PSK setiap bulan sebanyak 1.500 kondom. $^{7}$

Tetapi upaya tersebut kurang mendapatkan tanggapan dari pemilik barak maupun dari PSK itu sendiri.Distribusi kondom dari gudang obat Puskesmas Belawan yang dibagikan setiap bulan tidak pernah habis atau hanya sekitar 60\%-65\% terpakai setiap bulan. Persediaan kondom di gudang obat Puskesmas menumpuk tidak sebanding dengan permintaan penggunaan kondom oleh para pemilik barak.

Berdasarkan survei awal di lokasi penelitian, berbagai alasan dikemukakan pemilik barak seperti dengan adanya promosi kondom menurunkan jumlah pelanggan ke barak mereka, sedangkan alasan PSK mengapa tidak konsisten dalam menggunakan kondom ketika berhubungan karena pasangan tidak mau menggunakan kondom dengan alasan tidak nyaman, pelanggan yang sudah terlanjur nafsu tidak mau menggunakan kondom, pelanggan adalah raja sehingga kemauan pelanggan harus dituruti termasuk untuk tidak menggunakan kondom saat melakukan hubungan seks. Penolakan penggunaan kondom oleh pelanggan juga dilakukan dengan berbagai cara. Selain meminta diskon tarif jika dipaksa menggunakan kondom, pelanggan juga mengancam pindah ke barak lain jika tetap diminta untuk memakai kondom saat berhubungan. Hal tersebut menyulitkan, karena para PSK tentu saja butuh pelanggan agar mendapat penghasilan.Sikap pelanggan yang berkeras tidak mau menggunakan kondom tidak lepas dari hubungan latar belakang mereka. Hal ini disebabkan profesi dan pendidikan sebagian para pengguna jasa PSK rendah dan pengetahuan tentang penyakit menular seksual juga rendah 
sehingga membuat mereka kurang sadar terhadap bahaya penyakit jika berhubungan seksual tanpa kondom. Dengan berkerasnya pelanggan tidak mau menggunakan kondom sehingga stok kondom yang ada di barak sering kali hanya menumpuk.Kondom yang dibagikan pada PSK dari puskesmas untuk ditawarkan pemakaiannya pada para pelanggan banyak yang tidak terpakai walaupun usaha pendistribusian kondom tetap dilakukan oleh Puskesmas Belawan.

Berdasarkan uraian di atas yang menjelaskan bahwa penggunaan kondom semakin menurun dan terbukti dari banyaknya kondom yang diberikan cumacuma tidak habis terpakai, dan ditemukannya 9 orang PSK dengan IMS dan HIV/AIDS di tahun 2016, maka peneliti ingin mengetahui lebih dalam tentang determinan penggunaan kondom pada penjaja seks komersial di kawasan Sicanang Belawan tahun 2017.

\section{Metode Penelitian}

Jenis penelitian adalah survei analitik atau explanatory (penjelasan) dengan desain cross sectional menggunakan metode campuran (mix method) kuantitatif dan kualitatif, yang menjelaskan determinan penggunaan kondom pada penjaja seks komesial (PSK) di kawasan Sicanang Belawan tahun 2017. Populasi dalam penelitian ini adalah seluruh wanita penjaja seks komersial (PSK) yang tinggal di barak-barak di wilayah kerja Puskesmas Belawan yaitu Barak Agen, Barak Agung, Barak Sempurna, Barak Oukup dan Barak Salon sebanyak 84 orang. Sampel dalam penelitian ini adalah keseluruhan populasi (total sampling) yaitu 84 orang dan informan dalam penelitian ini adalah mucikari.Pengolahan data dilakukan dengan menggunakan program statistik (Statistic/ Data analysis) dengan analisis univariat, bivariat, dan multivariat.

\section{Hasil Penelitian}

Identitas responden yang ditanyakan dalam penelitian ini meliputi umur, pendidikan terakhir, dan sudah berapa lama menjadi PSK. Dari hasil penelitian menunjukkan bahwa umur responden termuda yaitu 17 tahun sedangkan umur tertua yaitu 32 tahun. Mengacu pada umur responden berdasarkan nilai median (nilai tengah) maka sebagian besar responden berumur $\leq$ 24 tahun sebanyak 45 orang (53,6\%), selebihnya berumur $>24$ tahun sebanyak 39 orang (46,4\%). Hal tersebut sangat memungkinkan, mengingat pelanggan umumnya lebih menyukai PSK yang masih berusia muda karena dianggap lebih energik, gesit dan menarik.

\section{Karakteristik Responden}

Tabel 1. Distribusi Karakteristik Responden

\begin{tabular}{llll}
\hline Karakteristik & Kategori & $\mathbf{n}$ & $\mathbf{\%}$ \\
\hline Umur & $\leq 24$ tahun & 45 & 53,6 \\
& $\geq 24$ tahun & 39 & 46,4 \\
Pendidikan & SD & 20 & 23,8 \\
& SMP & 38 & 45,2 \\
Lama Menjadi & SMA & 26 & 31,0 \\
PSK & 2-3 tahun & 30 & 35,7 \\
& 4-5 tahun & 34 & 40,5 \\
& 6-7 tahun & 5 & 15,9 \\
\hline
\end{tabular}

Berdasarkan tingkat pendidikan sebagian besar responden berpendidikan SMPyaitu 38 orang (45,2\%), sebagian kecil berpendidikan SD yaitu 20 orang (23,8\%). Data tersebut menunjukkan rendahnya tingkat pendidikan PSK sehingga sangat memungkinkan sebagai penyebab mudahnya terjerumus kedalam praktek prostitusi. Akibat kurangnya pengetahuan disebabkan pendidikannya yang rendah, mereka menjadi lebih mudah dibujuk dan diiming-imingi kesenangan dan pekerjaan sehingga dengan gampang terjerumus kedalam praktek prostitusi

Berdasarkan lamanya menjadi PSK, sebagian besar responden menjadi PSK selama1 tahun yaitu 30orang (35,7\%), dan sebagian kecil sudah menjadi PSK selama 4 dan 6 tahun yaitu 2 orang (2,4\%). Data tersebut menunjukkan bahwa PSK yang sudah lama berprofesi kurang diminati oleh pelanggannya, sehingga pelanggan 
lebih menyukai PSK yang masih baru karena dianggap masih muda dan cantik.

\section{Analisis Univariat}

Tabel 2. Distribusi Frekuensi Variabel Penelitian Dalam Penggunaan Kondom di Kawasan Sicanang Belawan

\begin{tabular}{llll}
\hline Karakteristik & Kategori & n & \% \\
\hline Pengetahuan & Baik & 67 & 79,8 \\
& Kurang Baik & 17 & 20,2 \\
Persepsi & Baik & 17 & 20,2 \\
& Kurang Baik & 67 & 79,8 \\
Ketersediaan & Memadai & 47 & 56,0 \\
Kondom & Kurang & 37 & 44,0 \\
& Memadai & & \\
Kenyamanan & Nyaman & 55 & 65,5 \\
Pelanggan & Kurang nyaman & 29 & 34,5 \\
Dukungan & Baik & 47 & 56,0 \\
Mucikari & Kurang Baik & 37 & 44,0 \\
Dukungan & Baik & 72 & 85,7 \\
Tenaga & Kurang Baik & 12 & 14,3 \\
Kesehatan & & & \\
Penggunaan & Selalu & 24 & 28,6 \\
Kondom & Kadang-Kadang & 60 & 71,4 \\
\hline
\end{tabular}

Pada tabel 2 diperoleh variabel pengetahuan sebagian besar pengetahuan responden dalam kategori baik yaitu 67 orang $(79,8 \%)$, selebihnya dalam kategori kurang baik yaitu 17 orang (20,2\%). Responden dalam kategori baik yaitu 67 orang (79,8\%), selebihnya dalam kategori kurang yaitu 17 orang (20,2\%). responden untuk variabel ketersediaan kondom sebagian besar menyatakan kurang memadai yaitu 37 orang (44,0\%), selebihnya menyatakan memadai yaitu 47 orang (56,0\%). Jawaban responden untuk variabel kenyamanan pelanggan sebagian besar menyatakan merasa kurang nyaman yaitu 29 orang (34,5\%), selebihnya merasa nyaman yaitu 55 orang (65,5\%). Hasil dari variabel dukungan mucikari sebagian besar menyatakan dukungan mucikari baik yaitu 47 orang (56,0\%), selebihnya menyatakan kurang baik yaitu 37 orang (44,0\%). Pada variabel dukungan tenaga kesehatan sebagian besar menyatakan dukungan tenaga kesehatan baik yaitu 72 orang (85,7\%), selebihnya menyatakan kurang yaitu 12 orang (14,3\%). Berdasarkan variabel penggunaan kondom, sebagian besar menyatakan kadang-kadang menggunakan kondom yaitu 49 orang (58,3\%), selebihnya menyatakan selalu yaitu 35 orang $(41,7 \%)$.

\section{Analisis Bivariat}

Berdasarkan tabel di atas dapat dilihat bahwa hasil penelitian hubungan pengetahuan dengan penggunaan kondom menunjukkan bahwa Hasil uji statistik dengan ujiChi-Square menunjukkan ada hubungan yang signifikan antara pengetahuan dengan penggunaan kondom, nilai $\mathrm{p}=0,002<0,05$.

Tabel 3. Analisis Bivariat

\begin{tabular}{|c|c|c|c|c|c|c|}
\hline \multirow{3}{*}{ Variabel } & \multirow{3}{*}{ Kategori } & \multicolumn{4}{|c|}{ Penggunaan Kondom } & \multirow{3}{*}{$\begin{array}{c}\mathbf{p} \\
\text { value }\end{array}$} \\
\hline & & \multicolumn{2}{|c|}{ Selalu } & \multicolumn{2}{|c|}{ Kadang-Kadang } & \\
\hline & & $\mathbf{n}$ & $\%$ & $\mathbf{n}$ & $\%$ & \\
\hline \multirow[t]{2}{*}{ Pengetahuan } & Baik & 24 & 28,6 & 43 & 51,2 & \multirow{2}{*}{0,002} \\
\hline & Kurang Baik & 0 & 0 & 17 & 20,2 & \\
\hline \multirow{2}{*}{ Persepsi } & Baik & 7 & 8,3 & 10 & 12,0 & \multirow{2}{*}{0,234} \\
\hline & Kurang Baik & 17 & 20,2 & 50 & 59,5 & \\
\hline Ketersediaan & Memadai & 21 & 25,0 & 26 & 30,9 & \multirow{2}{*}{0,001} \\
\hline Kondom & Kurang Memadai & 3 & 3,6 & 34 & 40,5 & \\
\hline Kenyamanan & Nyaman & 21 & 25,0 & 34 & 40,5 & \multirow{2}{*}{0,015} \\
\hline Pelanggan & Kurang Nyaman & 3 & 3,6 & 26 & 30,9 & \\
\hline Dukungan & Baik & 3 & 3,6 & 21 & 25,0 & \multirow{3}{*}{0,001} \\
\hline Mucikari & Kurang Baik & 26 & 30,9 & 34 & 40,5 & \\
\hline Dukungan & Baik & 20 & 23,8 & 52 & 61,9 & \\
\hline $\begin{array}{l}\text { Tenaga } \\
\text { Kesehatan }\end{array}$ & Kurang Baik & 4 & 4,8 & 8 & 9,5 & 0,735 \\
\hline
\end{tabular}


Hasil uji statistik dengan uji Chi-Square menunjukkan tidak ada hubungan yang signifikan antara persepsi dengan penggunaan kondom, nilai $\mathrm{p}=0,234>$ 0,05. Hasil uji statistik dengan uji ChiSquare menunjukkan ada hubungan yang signifikan ketersediaan kondom dengan penggunaan kondom, nilai $\mathrm{p}=0,001$ $>0,05$. Hasil uji statistik dengan uji ChiSquare menunjukkan ada hubungan yang signifikan kenyamanan pelanggan dengan penggunaan kondom, nilai $\mathrm{p}=0,015<0,05$. Hasil uji statistik dengan uji Chi-Square menunjukkan ada hubungan yang signifikan antara dukungan mucikari dengan penggunaan kondom, nilai $\mathrm{p}=$ $0,015<0,001$. Hasil uji statistik dengan uji Chi-Square menunjukkan tidak ada hubungan yang signifikan antara dukungan petugas kesehatan dengan penggunaan kondom, nilai $\mathrm{p}=0,735>0,05$.

\section{Analisis Multivariat}

Hasil analisis multivariat dengan uji regresi logistik diperoleh hasil bahwa variabel yang berhubungan signifikan terhadap penggunaan kondom yaitu variabel dukungan mucikari $(p=0,004)$, sedangkan variabel yang tidak berhubungan yaitu pengetahuan $(\mathrm{p}=$ $0,998)$, ketersediaan kondom $(p=0,102)$, dan kenyamanan pelanggan $(\mathrm{p}=0,243)$. Nilai $P$ value yang paling signifikan yaitu variabel dukungan mucikari sebesar $(0,004)<0,05$ maka Ho ditolak dapat diartikan bahwa terdapat hubungan yang signifikan dukungan mucikari terhadap pemakaian kondom dengan nilai koefisien hubungan1.993. Dari nilai $\operatorname{Exp(B)~dapat~}$ dilihat bahwa dukungan mucikari dalam penggunaan kondom 7,335 kali lebih besar dibandingkan yang tidak mendapatkan dukungan mucikari. Nilai (B) sebesar 1.993 artinya bahwa peningkatan dukungan mucikari sebesar 1 , akan ada memberikan perubahan positif sebesar 1.993 dalam penggunaan kondom. Dengan demikian bahwa jika ada peningkatan dukungan mucikari dari rendah ke tinggi akan meningkatkan probabilitas pemakaian kondom sebesar 1.993 kali.

Tabel 4. Hasil Analisis Multivariat Uji Regresi Logistik

\begin{tabular}{lccc}
\hline \multicolumn{1}{c}{ Variabel } & B & Sig & Exp(B) \\
\hline Pengetahuan & 19.490 & 0.998 & 291325631.797 \\
Ketersediaan Kondom & 1.273 & 0.102 & 3.570 \\
Kenyamanan Pelanggan & 0.897 & 0.243 & 2.407 \\
Dukungan Mucikari & 1.993 & 0.004 & 7.335 \\
\hline
\end{tabular}

Pembahasan

Hubungan Pengetahuan $\begin{aligned} & \text { Terhadap } \\ & \text { Penggunaan Kondom di } \\ & \text { Sicanang Belawan }\end{aligned}$
Kawan

Berdasarkan hasil penelitian hubungan pengetahuan dengan penggunaan kondom menunjukkan bahwa dari 67 responden yang berpengetahuan baik sebagian besar kadang-kadang menggunakan kondom yaitu 43 orang (51,2\%), sedangkan dari 17 responden yang berpengetahuan kurang baik seluruhnya mengatakan kadang-kadang menggunakan kondom yaitu 17 orang (20,2\%). Hasil uji statistik dengan uji Chi-
Square menunjukkan ada hubungan yang signifikan antara pengetahuan dengan penggunaan kondom, nilai probabilitas (p) $=0,002<0,05$.

Pengetahuan yang baik merupakan domain yang sangat penting untuk terbentuknya tindakan seseorang dalam hal ini tindakan untuk menggunakan kondom. Penggunaan kondom yang lebih konsisiten ditemukan pada kelompok yang memiliki pengetahuan komperhensif. Kondom gratis juga memhubungani konsistensi penggunaan kondom karena terkait dengan aksebilitas. Frekuensi kontak dengan petugas lapangan menigkatkan 
kemungkinan penggunaan kondom konsisten. Selain itu, penggunaan kondom konsisten dihubungani oleh adanya aturan penggunaan kondom. Sekitar 60\% PSK mengaku menggunakan kondom karena adanya peraturan baik formal maupun nonformal. ${ }^{5}$

Berdasarkan hasil wawancara dengan PSK dan Mucikari diketahui bahwa meskipun secara fisik mereka tahu tentang kondom karena sering menggunakannya, demikian juga fungsinya untuk mencegah penularan penyakit kelamin dan HIV/AIDS, tetapi mereka tidak tahu cara penularan penyakit HIV/AIDS maupun tanda dan gejala penyakit HIV/AIDS. Menurutnya, dengan salaman dapat menularkan penyakit HIV/AIDS. Jika dilihat dari karakteristik PSK berdasarkan umur bahwa 45 orang berada pada kategori $\leq 24$ tahun dan rata-rata sudah bekerja selama 2-3 tahun. Berdasarkan hal tersebut dapat di ambil asumsi bahwa semakin lama PSK bekerja, maka semakin baik pengetahuannya.

\section{Hubungan Persepsi Terhadap Penggunaan Kondom di Kawasan Sicanang Belawan}

Berdasarkan hasil penelitian sebagian besar persepsi responden dalam kategori baik yaitu 67 orang (79,8\%), selebihnya dalam kategori kurang yaitu 17 orang (20,2\%). Berdasarkan hasil penelitian hubungan persepsi dengan penggunaan kondom menunjukkan bahwa dari 67 responden yang memiliki persepsi baik sebagian besar kadang-kadang menggunakan kondom yaitu 50 orang (59,5\%), sedangkan dari 17 responden yang memiliki persepsi kurang sebagian besar juga kadang-kadang menggunakan kondom yaitu 10 orang (11,9\%). Hasil uji statistik dengan uji Chi-Square menunjukkan tidak ada hubungan yang signifikan antara persepsi dengan penggunaan kondom, nilai probabilitas (p) $=0,234>0,05$.

Persepsi merupakan suatu proses yang timbul akibat adanya aktifitas (pelayanan yang diterima) yang dapat dirasakan oleh suatu objek. Mengingat bahwa persepsi setiap orang terhadap suatu objek (pelayanan) akan berbeda-beda. Oleh karena itu persepsi memiliki sifat subjektif yang merupakan suatu rasa puas atau tidakoleh adanya pelayanan yang diterima. $^{8}$

Berdasarkan wawancara dengan PSK diketahui bahwa persepsinya tentang penggunaan kondom dan penyakit HIV/AIDS masih keliru. Mereka menganggap bahwa penyakit HIV/AIDS tidak mematikan, penyakit tersebut hanya menyerang kaum homoseks (gay), melakukan hubungan seks dengan orang yang dianggap ganteng (cakep) atau kaya dianggap lebih bersih dan tidak menularkan penyakit kelamin ataupun penyakit HIV/AIDS.

\section{Hubungan Ketersedian Kondom Terhadap Penggunaan Kondom di Kawasan Sicanang Belawan}

Berdasarkan hasil penelitian hubungan ketersediaan kondom dengan penggunaan kondom menunjukkan bahwa dari 47 responden yang menyatakan ketersediaan kondom yang memadai sebagian besar kadang-kadang menggunakan kondom yaitu 26 orang (30,9\%),sedangkan dari 37 responden yang menyatakan ketersediaan kondom kurang memadai sebagian besar juga kadangkadang menggunakan kondom yaitu 34 orang (40,5\%). Hasil uji statistik dengan uji Chi-Square menunjukkan ada hubungan yang signifikan ketersediaan kondom dengan penggunaan kondom, nilai probabilitas $(p)=0,001>0,05$.

Lokalisasi Pemandangan Teluk Betung Selatan Bandar Lampung bahwa responden yang menyatakan bahwa kondom tidak selalu tersedia sebanyak 53,5\%. Variabel ketersediaan kondom dengan penggunaan kondom berhubungan signifikan dengan konsistensi pamakaian kondom $(P$ value $=0,003){ }^{2}$

Berdasarkan hasil wawancara dengan PSK diketahui bahwa para PSK tahu 
bahwa petugas puskesmas sering memberikan kondom gratis ke barak-barak mereka, tetapi mereka lebih sering membelinya dari mami atau di apotek. Menurut mereka, kondom gratis itu tidak ada, yang ada uang pendapatan mereka dari pelanggan dipotong oleh mucikari.

\section{Hubungan Kenyamanan Pelanggan Terhadap Penggunaan Kondom di Kawasan Sicanang Belawan}

Berdasarkan hasil penelitian hubungankenyamanan pelanggan dengan penggunaan kondom menunjukkan bahwa dari 55 responden yang menyatakan bahwa pelanggan merasa nyaman sebagian besar kadang-kadang tidak menggunakan kondom yaitu 34 orang (40,5\%), sedangkan dari 29 responden yang menyatakan pelanggan merasa kurang sebagian besar kadang-kadang menggunakan kondom yaitu 26 orang (30,9\%). Hasil uji statistik dengan uji ChiSquare menunjukkan ada hubungan yang signifikan kenyamanan pelanggan dengan penggunaan kondom, nilai probabilitas (p) $=0,015<0,05$.

Desa Firdaus menemukan bahwa posisi tawar PSK Warung Bebek rendah, walaupun mereka mengetahui bahaya HIV//AIDS dan memiliki strategi dalam menigkatkan posisi tawar. Dukungan petugas kesehatan dan LSM terhadap PSK Warung Bebek dengan memantau dan memberi bimbingan dalam hasil pencegahan HIV/AIDS. Pihak pemerintahan terdiri dari TPA dan Dinas sosial sedangkan dari pihak non pemerintah antara lain Yayasan Peduli AIDS (YPA). ${ }^{9}$

Keberadaan PSK di Kawasan Sicanang Belawan merupakan salah satu pemeran penting dalam program pencegahan dan penanggulangan HIV/AIDS.Walaupun termasuk dalam pemeran penting, namun kenyataaanya posisi mereka sangat lemah.Sebagai target sasaran kebijakan para PSK tidak memiliki posisi tawar yang kuat dalam bernegosiasi seks secara sehat dengan pelangganya.
Program penggunaan kondom yang dibeli untuk menekan laju penularan penyakit IMS dan HIV/AIDS belum dapat dijalankan secara maksimal.Posisi mereka yang sebenarnya sangat potensi dalam mencegah penyebaran HIV/AIDS khususnya dilokalisasi, namaun kenyataanya mudah diintervensi oleh mucikari ataupun dari pelanggan itu sendiri.

Berdasarkan hasil wawancara dengan PSK di Kawasan Sicanang Belawan Belawan para PSK mengerti bahwa menggunakan kondom agar terhindar dari berbagai penyakit menular seksual, tapi selalu saja ada pelangan yang menolak untuk selalu menggunakan kondom dengan alasan kondom menghambat kesenangan, sensasi fisik dan aliran perasan secara bebas pada pasangan seksualnya. PSK juga mendapatkan pelanggan dengan berbagai tipe, ada yang mau menerima anjuran agar mengunakan kondom, ada yang menolak bahkan mengancam pindah ke barak lain sehingga PSK sekering kali harus meladeni pelanggan walaupun tidak menggunakan kondom saat melakukan hubungan seks, dari pada kehilangan pemasukan.

\section{Hubungan Dukungan Mucikari Dengan Penggunaan Kondom di Kawasan Sicanang Belawan}

Berdasarkan hasil penelitian hubungan dukungan mucikari dengan penggunaan kondom menunjukkan bahwa dari 24 responden yang menyatakan bahwa dukungan mucikari baik sebagian besar kadang-kadang tidak menggunakan kondom yaitu 21 orang (25,0\%), sedangkan dari 60 responden yang menyatakan dukungan mucikari kurang baik sebagian besar kadang-kadang menggunakan kondom yaitu 26 orang (30,9\%). Hasil uji statistik dengan uji ChiSquare menunjukkan ada hubungan yang signifikan antara dukungan mucikari dengan penggunaan kondom, nilai probabilitas $(\mathrm{p})=0,015<0,05$.

Hasil persamaan regresi logistik di atas tidak bisa langsung diinterpretasikan 
dari nilai koefisienya seperti regresi liner biasa. Interpretasi dapat dilakukan dengan melihat nilai dari $\operatorname{Exp(B)}$ atau nilai eksponen dari koefisien persamaan regresi yang terbentuk.Dari $\operatorname{Exp}(\mathrm{B})$ dapat dilihat bahwa dukungan mucikari mempunyai kesempatan memakai kondom 7.335 kali lebih dibandingkan dengan responden yang tidak mendapatkan dukungan mucikari. Nilai (B) sebesar 1.993 artinya bahwa peningkatan dukungan mucikari sebesar 1 akan ada perubahan sebesar 1.993 pada pemakaian kondom. Dengan demikian bahwa jika ada peningkatan dukungan mucikari dari rendah ke tinggi akan meningkatkan probabilitas pemakaian kondom sebesar 1.993 kali.

Definisi dukungan sosial banyak di sampaikan oleh para ahli salah satunya adalah menurut Sheridan dan Radmacher lewat interaksi dengan orang lain. "Social spport is the resources provided to us trough our interaction with other people” Dukungan sosial adalah derajat dukungan yang diberikan kepada individu kshususnya sewaktu dibutuhkan oleh orang-orang yang memiliki hubungan emosional yang dekat dengan orang tersebut. Dukungan juga bisa dalam bentuk pemberian rasa kenyamanan, pengakuan, kepercayaan seseorang dan bantuan langsung dalam bentuk tertentu.Seorang PSK akan merasa nyaman, merasa mendapat kepercayaan oleh mucikarinya, diperbolehkan menggunakan kondom dalam memberikan pelayanan terhadap pelanggan, hubungan inilah yang disebut sebagai salah satu bentuk dukungan. ${ }^{10}$

Dari hasil wawancara dapat dilihat bahwa beberapa mucikari meminta PSK nya untuk menggunakan kondom, tapi tidak bisa mengawasi pemakaiannya. Mucikari cenderung tegas pada hal lain, misalnya jika setoran PSK tidak sesuai yang diharapkan atau jika PSK terkesan tidak serius melayani pelanggan, maka terkadang mucikari menggunakan kekerasan fisik jika PSK membantah atau melawannya.

\section{Hubungan Dukungan Tenaga \\ Kesehatan Dengan Pengguanaan Kondom di Kawasan Sicanang Belawan}

Berdasarkan hasil penelitian hubungan dukungan petugas kesehatan dengan penggunaan kondom menunjukkan bahwa dari 72 responden yang menyatakan bahwa dukungan petugas kesehatan baik sebagian besar kadang-kadang menggunakan kondom yaitu 52 orang (61,9\%), sedangkan dari 12 responden yang menyatakan dukungan petugas kesehatan kurang baik sebagian besar juga kadang-kadang menggunakan kondom yaitu 8 orang $(9,5 \%)$. Hasil uji statistik dengan uji Chi-Square menunjukkan tidak ada hubungan yang signifikan antara dukungan petugas kesehatan dengan penggunaan kondom, nilai probabilitas (p) $=0,735>0,05$.

Hasil bahwa dukungan petugas kesehatan sebesar 59,2\%. Terdapat hubungan yang signifikan antara dukungan petugas kesehatan dengan konsistensi penggunaan kondom di Eks Lokalisasi Pemandangan Teluk Betung Selatan Bandar Lampung (p-value $=0,007){ }^{10}$

Dukungan petugas kesehatan dalam memberikan penyuluhan dan pemeriksaan kesehatan pada PSK menurut sebagian besar responden sudah baik, tetapi tingkat penggunaan kondom masih rendah, hal ini dikarenakan pendidikan PSK sebagian masih rendah yaitu berpendidikan SD dan SMP sehingga pemahaman dan pengetahuan tentang penggunaan kondom dan penyakit menular seksual (HIV/AIDS) belum optimal. Sering juga ditemukan bahwa beberapa PSK tidak mau mengikuti kegiatan penyuluhan yang diadakan petugas kesehatan karena merasa bahwa kegiatan tersebut membosankan, sehingga perlu dipikirkan cara penyampaian informasi dalam penyuluhan oleh petugas lebih inovatif dan merangsang minat PSK untuk mengikuti penyuluhan.

Hasil penelitian ini berdasarkan jawaban responden dari kuesioner menunjukkan bahwa menurut sebagian besar PSK bahwa petugas kesehatan telah 
memberikan dukungan yang baik dalam menurunkan penularan penyakit menular dan HIV/AIDS melalui program pendistribusian kondom maupun penyuluhan, tetapi PSK tetap mempunyai posisi tawar yang rendah kepada pelanggan dalam penggunaan kondom. Sebagian PSK sudah mendapatkan informasi dan memahami pentingnya penggunaan kondom dalam berhubungan seksual untuk pencegahan penyakit menular seksual namun mereka harus tunduk pada permintaan pelanggan.

\section{Penggunaan Kondom Oleh PSK Di} Kawasan Sicanang Belawan Tahun 2017

Hasil penelitian tentang penggunaan kondom oleh pekerja seks komersial (PSK) di Kawasan Sicanang Belawan sebagaian besar responden kadang-kadang menggunakan kondom saat melakukan hubungan seks dengan pelanggan yaitu 60 orang (71,4 \%), selebihnya menyatakan selalu yaitu 24 (28,6\%) orang.

Hubungan seksual pada kelompok ini (PSK) tanpa menggunakan kondom merupakan prilaku yang beresiko tinggi terhadap penularan HIV (Nurkholis, 2008).Sosialisasi penggunaan kondom selain merupakan alat kontrasepsi sah dalam Program Keluarga Berencana juga sebagai usaha mereduksi penulairan HIV/AIDS menjadi hal yang darurat.Besarnya peran alat kontrasepsi kondom dalam penularan penyakit menular seksual dan HIV/AIDS sehingga PBB, United Nations Population Fund Development (UNPFD) memfokuskan pada program promosi kondom. Demikian juga dengan departemen kesehatan yang didukung oleh Family Health International yang mencanangkan kampanye kondom secara terbuka sebagai upaya menigkatkan kepedulian dan pencegahan penularan HIV/AIDS. ${ }^{11}$

Berdasarkan hasil wawancara dengan PSK dan mucikari bahwa penggunaan kondom selalu dianjurkan oleh mucikari pada anak asuhnya, dan para PSK juga menganjurkan pelanggan agar menggunakan kondom setiap melakukan hubungan seks. Tetapi karena posisi tawar PSK lemah sebagai orang yang dibayar, maka mereka seringkali menuruti kemauan pelanggan, kadang-kadang tidak menggunakan kondom apalagi jika pelanggan kelihatan bersih, sehat dan ganteng.

\section{Kesimpulan}

Sesuai dengan hasil penelitian diperoleh kesimpulan bahwa pengetahuan, ketersediaan kondom, kenyamanan pelanggan, dukungan mucikari, berhubungandengan penggunaan kondom pada PSK di Kawasan Sicanang Belawan tahun 2017, sedangkan persepsi dan dukungan tenaga kesehatan tidak berhubungan. Determinan penggunaan kondom oleh PSK adalah dukungan mucikari.PSK yang mendapat dukungan mucikari mempunyai kesempatan menggunakan kondom 7,335 kali lebih besar dibandingkan dengan PSK yang tidak mendapatkan dukungan mucikari. Peningkatan dukungan mucikari dari rendah ke tinggi akan meningkatkan probabilitas pemakaian kondom sebesar 1.993 kali.

\section{Saran}

Dengan demikian hendaknya Dinas Kesehatan Kota Medanmelakukan pelatihan-pelatihan secara berkala bagi tenaga kesehatan di setiap Puskesmas seKota Medan yang dijadikan sebagai konselor pencegahan penularan penyakit menular seksual dan HIV/AIDS agar mampu menggunakan metode yang dapat merubah persepsi dan sikap PSK tentang kondom dan penyakit menular seksual menjadi lebih baik, membuat kebijakan (regulasi) tentang kewajiban penggunaan kondom bagi PSK dan pelanggan agar penularan atau penyebaran penyakit menular seksual dan HIV/AIDS dapat ditekan, serta mengupayakan program Komunikasi Informasi dan Edukasi (KIE) pada PSK yang lebih komprehensif dan sering. 


\section{Daftar Pustaka}

1. Cunningham FG. William Obstetri. Edisi 23, Vol.2. Jakarta: EGC; 2012.

2. Fahmi S, Indratmi W, dan Zubeir F. Infeksi Menular Seksual. Jakarta: FKUI; 2014.

3. WHO. Global HIV/AIDS Respons, Progress Report 2014; 2014.

4. Kemenkes RI. Surveilans Terpadu Biologis dan Perilaku (STBP) Tahun 2011. Jakarta: Direktorat Jenderal Pengendalian Penyakit dan Penyehatan Lingkungan Kementrian Kesehatan Republik Indonesia. 2014b.

5. Kemenkes RI. Statistik Kasus HIV/AIDS di Indonesia. Jakarta: Direktorat Jenderal PPM \& PL Kementerian Kesehatan Republik Indonesia. 2014a.

6. Dinkes Propsu, Profil Kesehatan Propinsi Sumatera Utara Tahun 2010. Medan: Dinas Kesehatan Propinsi Sumatera Utara, 2014
7. Puskesmas Belawan, Data Penderita HIV/AIDS di Wilayah Kerja Puskesmas Belawan.Belawan : Puskesmas Belawan; 2016.

8. Syafrudin, Siti Masitoh, dan Taty R. Manajemen Mutu Pelayanan Kesehatan Untuk Bidan. Cetakan Pertama, Jakarta: Trans Info Media; 2011.

9. Pinem S. Kesehatan Reproduksi dan Kontrasepsi. Cetakan Pertama, Jakarta: Trans Info Media; 2009.

10. Sarwono S. Sosiologi Kesehatan. Cetakan Ketiga. Yogyakarta: Gadjah Mada University Press: 2010.

11. KPA Nasional, Kebijakan Nasional Dalam Penanggulangan HIV/AIDS. Jakarta: Komisi Penanggulangan AIDS Nasional. 2012. 